\title{
Abfraction lesions: etiology, diagnosis, and treatment options
}

This article was published in the following Dove Press journal:

Clinical, Cosmetic and Investigational Dentistry

3 May 2016

Number of times this article has been viewed

\author{
Marcelle M Nascimento' \\ Deborah A Dilbone' \\ Patricia NR Pereira' \\ Wagner R Duarte ${ }^{2,3}$ \\ Saulo Geraldeli' \\ Alex J Delgado' \\ 'Department of Restorative Dental \\ Sciences, Division of Operative \\ Dentistry, ${ }^{2}$ Department of \\ Periodontology, College of Dentistry, \\ University of Florida, Gainesville, FL, \\ USA; ${ }^{3}$ Private Practice, Brasilia, \\ DF, Brazil
}

Correspondence: Marcelle M Nascimento Department of Restorative Dental Sciences, Division of Operative Dentistry, University of Florida, 1395 Center Drive, Room D9-6,

PO Box 100415, Gainesville,

FL 32610-04I5, USA

$\mathrm{Tel}+\mathrm{I} 3522735858$

Fax + I 352846 I643

Email mnascimento@dental.ufl.edu
Abstract: Abfraction is a type of noncarious cervical lesion (NCCL) characterized by loss of tooth tissues with different clinical appearances. Evidence supports that abfraction lesions, as any NCCLs, have a multifactorial etiology. Particularly, the cervical wear of abfraction can occur as a result of normal and abnormal tooth function and may also be accompanied by pathological wear, such as abrasion and erosion. The interaction between chemical, biological, and behavioral factors is critical and helps to explain why some individuals exhibit more than one type of cervical wear mechanism than others. In an era of personalized dentistry, patient risk factors for NCCLs must be identified and addressed before any treatment is performed. Marked variations exist in dental practice concerning the diagnosis and management of these lesions. The lack of understanding about the prognosis of these lesions with or without intervention may be a major contributor to variations in dentists' management decisions. This review focuses on the current knowledge and available treatment strategies for abfraction lesions. By recognizing that progressive changes in the cervical area of the tooth are part of a physiologically dynamic process that occurs with aging, premature and unnecessary intervention can be avoided. In cases of asymptomatic teeth, where tooth vitality and function are not compromised, abfraction lesions should be monitored for at least 6 months before any invasive procedure is planned. In cases of abfraction associated with gingival recession, a combined restorative-surgical approach may be performed. Restorative intervention and occlusal adjustment are not indicated as treatment options to prevent further tooth loss or progression of abfraction. The clinical decision to restore abfraction lesions may be based on the need to replace form and function or to relieve hypersensitivity of severely compromised teeth or for esthetic reasons.

Keywords: abfraction, tooth wear, noncarious cervical lesions, tooth restoration

\section{Introduction}

Noncarious cervical lesions (NCCLs) develop as a result of normal and abnormal or pathological wear and cause abfraction, abrasion, and erosion or chemical degradation of dental tissues. ${ }^{1}$ Clinical appearance of NCCLs can vary depending on the type and severity of the etiological factors involved. ${ }^{2}$ Of all possible etiological factors for NCCLs, occlusal stress forces have received maximum attention over the years. Tensile stress from malocclusion and masticatory forces was initially proposed as the primary factor in NCCLs; ${ }^{3}$ shortly thereafter, these lesions were termed as abfraction lesions. ${ }^{4}$ Despite many efforts to demonstrate that occlusal forces are the main cause of abfraction, its etiology remains poorly understood and controversial. ${ }^{5}$ Nowadays, it is generally incorrect to designate only one mechanism to be the cause of any type of NCCLs. ${ }^{6}$ Instead, current evidence supports a multifactorial etiology for all NCCLs 
with patient factors being responsible for the various degrees of tooth loss. ${ }^{7-10}$ Figure 1 shows the scheme of pathodynamic mechanisms responsible for initiation and perpetuation of NCCLs, as proposed by Grippo et al. ${ }^{6}$

NCCLs are relatively common clinical conditions that can adversely affect structural integrity, retention of dental plaque, tooth sensitivity, pulpal vitality, and esthetics..$^{5,9,11}$ The incidence of NCCLs is expected to increase as the population ages and teeth are retained longer; however, marked variations exist in dental practice concerning the diagnosis and management of these lesions. ${ }^{12}$ Treatment planning is primarily based on dentists' beliefs about the effectiveness of restorative or alternative interventions in terms of longevity and minimization of further tooth loss. ${ }^{13} \mathrm{~A}$ dental practicebased study revealed that NCCLs are the main reason other than caries for placement of restorations on previously unrestored permanent tooth surfaces. ${ }^{14}$ Nonetheless, the limited longevity of NCCL restorations is a continuing issue in dentistry, ${ }^{15}$ and unfortunately, no evidence-based guidelines are available in the literature to assist dentists regarding when and how these tooth defects should be restored. Noticeably, clinicians have long been misled by articles that proposed treatment recommendations for abfraction without credible scientific data. This review aims to provide insights on where abfraction lesions stand in research and clinical practice today by presenting the current knowledge and treatment options for these lesions.

\section{Theory of abfraction}

Abfraction means "to break away", a term derived from the Latin words "ab", or "away" and "fractio". "The theory of abfraction sustains that tooth flexure in the cervical area is caused due to occlusal compressive forces and tensile stresses, resulting in microfractures of the hydroxyapatite crystals of the enamel and dentin with further fatigue and deformation of the tooth structure. ${ }^{16-18}$ Abfraction lesions are also said to be facilitated by the thin structure of the enamel and the low packing density of the Hunter-Schreger band (HSB) at the cervical area. ${ }^{19}$ Many laboratory studies have attempted to reproduce the phenomenon of stress distribution

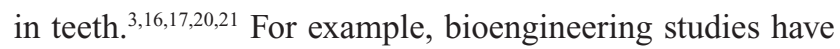
explored the association between occlusal stress and cervical wear by employing finite elemental analysis or photoelastic methods..$^{3,20,22,23}$ However, the few clinical studies available were not able to confirm a positive association between occlusal loading and abfraction lesions. ${ }^{24-26}$ It has been argued that an occlusal load that is far from the cervical defect site cannot be considered as the cause of abfraction lesions. ${ }^{27}$ Overall, there is a weak association between NCCLs and occlusal factors (interference in excursive movements, force, premature contacts, type of guidance, and slide of centric occlusion to maximum intercuspation).

It is apparent in clinical practice that not all patients with abfraction lesions present occlusal wear (bruxism or clenching), and not all patients with occlusal wear exhibit

\section{Schema of pathodynamic mechanisms of tooth surface lesions}

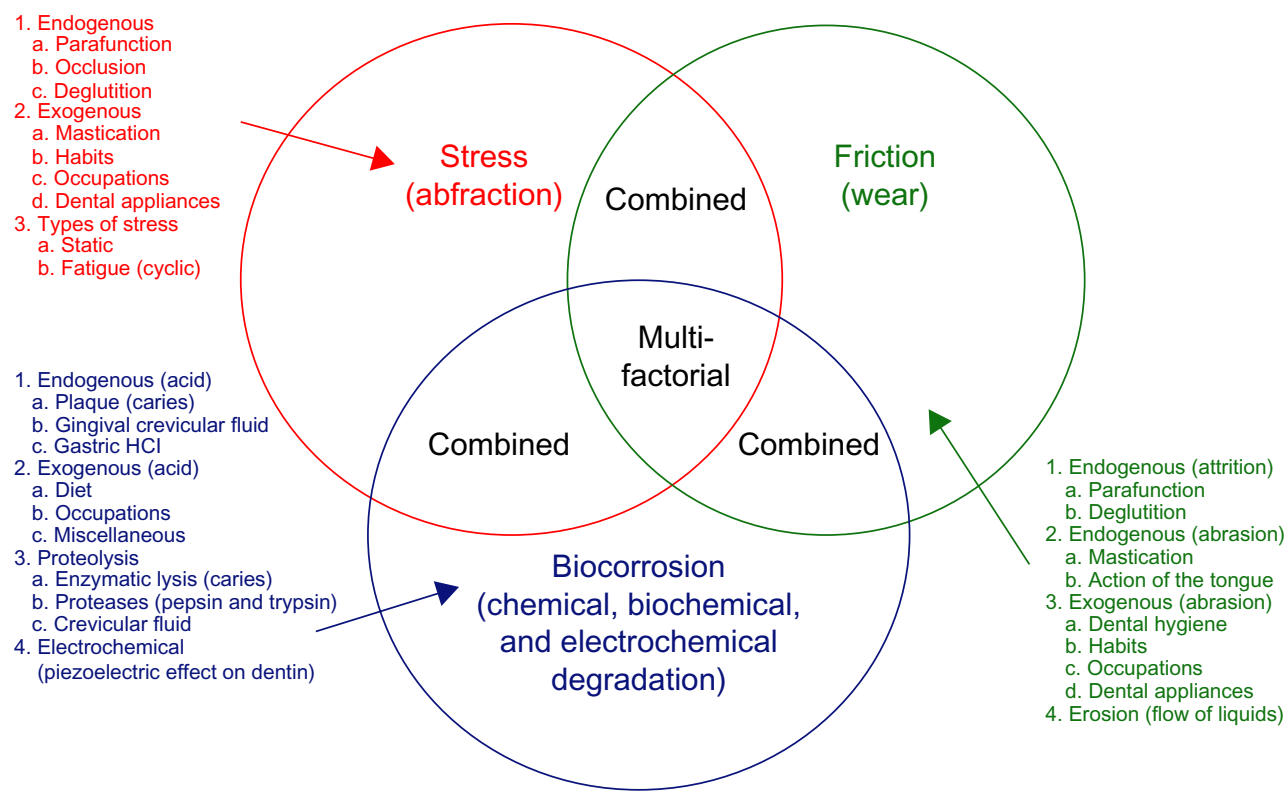

Figure I Scheme of pathodynamic mechanisms involved in NCCLs as proposed by Grippo et al. ${ }^{6}$

Note: (C) 2011 Wiley Periodicals, Inc. Reproduced from John Wiley and Sons. Grippo JO, Simring M, Coleman TA. Abfraction, abrasion, biocorrosion, and the enigma of noncarious cervical lesions: a 20-year perspective. J Esthet Restor Dent. 2012;24(1): 10-23. ${ }^{6}$

Abbreviations: $\mathrm{NCCL}$, noncarious cervical lesion; $\mathrm{HCl}$, hydrochloric acid. 
NCCLs. ${ }^{25}$ Optical coherence tomography has been recently used to examine the relationship between the clinical incidence of occlusal wear and cervical demineralization with NCCL dimensions. ${ }^{28}$ The study suggests that dentin demineralization promotes the formation of NCCLs from an early stage, whereas occlusal stress is an etiological factor that contributes to the progression of these lesions. ${ }^{28}$ The role of occlusal loading in NCCLs appears to be part of a multifactorial event that may not necessarily follow the proposed, classic abfraction mechanism. ${ }^{6,29}$ Thus, the theory of abfraction is yet to be proven.

\section{Diagnosis}

As with any clinical condition, the diagnosis of abfraction plays a significant role in the proper management of these lesions. This could be achieved with complete patient anamnesis accompanied by a careful clinical examination. Given that abfraction lesions have a multifactorial nature and contributing factors may change over time, it is imperative that all potential causal factors be evaluated while examining a patient with such cervical lesions. In addition to a thorough medical history, which should include an evaluation for gastroesophageal reflux disease, eating disorders, and dietary contributors, one should evaluate occlusion, parafunction, and oral habits, including occupational and ritual behaviors. ${ }^{30}$ The interaction between chemical, biological, and behavioral factors is critical and helps to explain why some individuals exhibit more than one type of cervical wear mechanism than others. The identification of patient factors that may be related to abfraction as well as the understanding of the most common clinical features of these lesions can certainly aid in diagnosis and, most importantly, assist the clinician to develop an appropriate treatment plan for individual patients.

Erosion processes are often associated with the diagnosis of abfraction lesions. Erosion is the progressive loss of dental hard tissue caused by acids from nonbacterial, intrinsic, or extrinsic sources. The term biocorrosion has also been proposed to include all forms of chemical, biochemical, and electrochemical degradation. ${ }^{6}$ Regurgitation may be an involuntary occurrence as a complication of gastrointestinal problems, or be patient-induced as in anorexia nervosa or bulimia. Dietary erosion occurs due to high consumption of foods or drinks containing a variety of acids, such as those from citrus and other fruits, fruit juices (citric acid), soft drinks, wine, and other carbonated drinks (carbonic acid and other acids). It has been reported that erosion or biocorrosion can also occur by the frequent use of acidic mouth rinses. ${ }^{6}$ The less frequent cases of industrial and environmental erosion have been associated to exposure to processes in the work place (eg, battery factories), which produce acid fumes or droplets, and leisure activities, such as swimming in chlorinated pools. ${ }^{31}$

The various clinical manifestations of abfraction appear to be dependent on the type and severity of the etiological factors involved. ${ }^{2}$ Figure 2 shows the presence of an advanced abfraction lesion in the second upper premolar of a patient presenting other types of cervical lesions, illustrating the multifactorial nature of NCCLs. The prevalence of NCCLs is greater in incisors and premolars than in canines and molars. ${ }^{8,11}$ Mandibular premolars are affected by NCCLs more often and more severely than maxillary premolars. ${ }^{8}$ Abfraction lesions and other NCCLs, such as erosion, may also affect the whole dentition in severe cases where aging is associated with other pathological factors, as shown in Figure 3.

Abfraction lesions are observed primarily on the buccal surfaces and are typically wedge- or V-shaped lesions with clearly defined internal and external angles. ${ }^{20}$ Researchers have also described that abfraction lesions can manifest themselves as C-shaped lesions with rounded floors or mixedshaped lesions with flat, cervical, and semicircular occlusal walls. ${ }^{32}$ Contributing factors leading to erosion or abrasion can also modify the clinical appearance of these lesions by making the angles less sharp and the outline broader and more saucer-shaped. Moreover, abfraction lesions may be deeper than wider depending on the stage of progression and related causal factors.

Multiple abfraction lesions overlapping one another, as the ones observed in Figure 4, seem to occur due to various forces producing tensile stress. ${ }^{3,9,20}$ The occasional cases of abfraction lesions that are detected below gingival

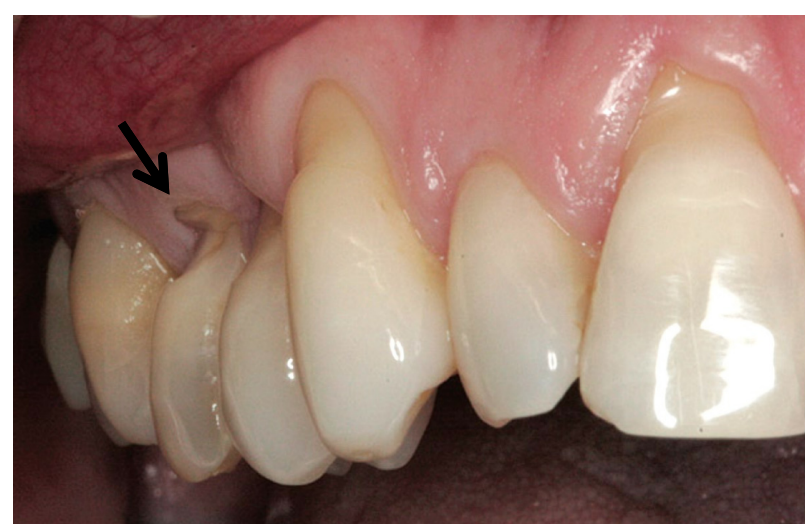

Figure 2 A typical abfraction lesion in a patient with multiple types of NCCLs. Notes: Arrow shows the second upper premolar with the typical lesion. Originally published in Inside Dentistry. (C) 20II AEGIS Publications, LLC. All rights reserved. Reprinted with permission of the publishers. ${ }^{70}$

Abbreviation: NCCL, noncarious cervical lesion. 


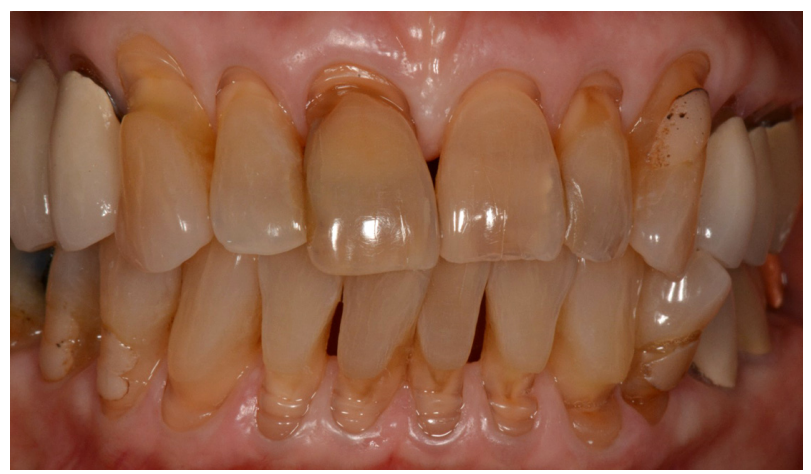

Figure 3 An elderly patient exhibiting NCCLs in the whole dentition. Note: Courtesy of Dr Alex J Delgado.

Abbreviation: NCCL, noncarious cervical lesion.

margins, beyond the reach of a toothbrush or other devices that could cause frictional forces, are also believed to have biomechanical loading forces as a major contributor. ${ }^{9}$ Likewise, a single tooth in a quadrant with an abfraction lesion is an indication that occlusal stress might be the primary contributing factor. ${ }^{9}$

Upon examination, shiny facets on the teeth or existing restorations may be indicators of the presence of erosive processes. Clinical features of erosive lesions also include broad concavities within smooth tooth enamel, loss of enamel surface anatomy, increase in incisal translucency, and incisal chipping and cupping out of occlusal surfaces with dentine exposure. Erosion caused by vomiting typically affects the palatal surfaces of the upper teeth, but this condition can also be caused by dietary acids. Diagnosis of erosion may not be easily accomplished because patients may not volunteer information as in cases of eating disorders, or patients may not link heartburn or stomach upsets with teeth defects. In addition, emphasis must be placed on medical conditions

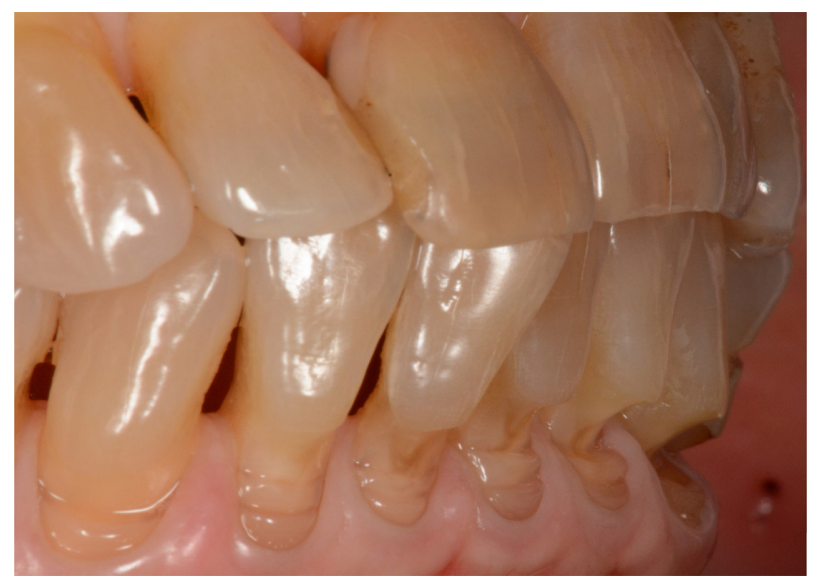

Figure 4 Abfraction lesions of different shapes, widths, and depths, characteristic of their different stages of progression. Note: Courtesy of Dr Alex J Delgado. that predispose teeth to erosion. Medical conditions and the use of medications that cause a reduction in salivary flow can aggravate the erosive effect on tooth surfaces. Referral and collaboration with medical practitioners may be necessary for further investigations, diagnosis, and management of these underlying medical conditions.

Abfraction lesions are more prevalent in the adult population, with the incidence increasing from $3 \%$ to $17 \%$ between 20 years and 70 years of age. ${ }^{4,9,10}$ The observation that premolar teeth of patients aged older than 40 years are the most common sites of restorations placed due to NCCLs highlights the importance of preventive interventions at an earlier age in order to avoid the need for future restorative or any other irreversible treatment. ${ }^{14}$ Evidently, the degree of occlusal and cervical wear increases with age and therefore should be considered as natural physiological processes. Wear facets may be found in the enamel, primary dentin, physiologic secondary dentin, and reparative (sclerotic) dentin. In rare cases, the wear is so extensive that it exposes the pulp. The defense mechanisms activated in teeth as a result of wear include the formation of reactionary and reparative dentin and the obstruction of exposed dentinal tubules by mineral deposits. ${ }^{1}$ The important point in this context is that odontoblast cells retain their ability to form dentin in vital teeth throughout the life of the tooth, and, if they are destroyed, mesenchymal precursor cells in the pulp are able to differentiate into new, odontoblast-like cells. ${ }^{33}$ By recognizing that progressive changes in the cervical area of the tooth, such as abfraction, are part of a physiologically dynamic process that occurs with aging, premature and unnecessary intervention can be avoided. ${ }^{34}$

The activity of abfraction lesions needs to be assessed and considered in the treatment planning process. Approaches to determine lesion activity include the use of standardized intra-oral photographs, study models, and measurement of lesion dimensions over time. Activity assessment can also be performed by using a scratch test. ${ }^{5}$ Visual observation of changes in the initial scratch created with a no 12 scalpel blade can offer an indication of the rate of tooth structure loss. Loss of the total or partial definition of the scratch may signify that the process is active. Furthermore, several indices of tooth wear have been proposed for recording and monitoring the progression of abfraction lesions or any NCCLs. ${ }^{35}$ The Smith and Knight index uses a scale from 0 to 4 , where $0=$ no change in contour, $1=$ minimal loss of contour, $2=$ defect $<1 \mathrm{~mm}$ deep, $3=$ depth of defect between $1 \mathrm{~mm}$ and $2 \mathrm{~mm}$, and $4=$ depth of defect $>2 \mathrm{~mm}$ or exposure of secondary dentin or pulp. ${ }^{36}$ Another index for NCCLs has 
been recently proposed that includes not only lesion depth but also the width and angle between the lesion and the occlusal and cervical walls, with a scale as follows: $1=$ buccolingual and occlusogingival $\leq 1 \mathrm{~mm}$ deep, is wedge- or V-shaped, and has an acute angle $\left(<90^{\circ}\right), 2=$ buccolingual and occlusogingival depths $>1 \mathrm{~mm}$ and up to $2 \mathrm{~mm}$, is saucer-shaped, and has an obtuse angle between $90^{\circ}$ and $135^{\circ}$, and $3=$ buccolingual and occlusogingival $>2 \mathrm{~mm}$ deep, is saucershaped, and has an obtuse angle $>135^{\circ} .{ }^{37}$ With the recent introduction of digital dentistry, future studies should also test if computer-aided design and computer-aided manufacturing (CAD-CAM) systems may be useful for diagnosis and monitoring of NCCL activity.

\section{Treatment options}

While several management strategies have been proposed to treat NCCLs, ${ }^{5,38-40}$ treatment planning for these lesions remains an area of great variability among dentists. ${ }^{12}$ The lack of clinical evidence about the prognosis of these lesions with or without intervention may be a major contributor to variations in dentists' management decisions. Some of the available treatment strategies may be tailored for abfraction lesions and others are used for NCCLs of all etiologies, depending on the patient factors and the severity of the problem. As discussed previously, successful prevention and management of abfraction or any NCCLs requires an understanding of the risk factors and how these risk factors change over time in individual patients. Preventive interventions may include counseling for changes in patient's behavior, such as diet, brushing technique, use of protective night guards to reduce clenching or bruxism, use of chewing gums to increase salivary flow, and/or to seek therapy or medical attention if there is a potential, intrinsic medical or mental condition. Other treatment options are reviewed below and include the following: monitoring of lesion progression, occlusal adjustments, occlusal splints, techniques to alleviate hypersensitity, placement of restorations, and root coverage surgical procedures in combination with restorations.

\section{Monitoring lesions}

The decision to monitor abfraction lesions rather than intervene should be based on the patient's age and how the lesion compromises tooth vitality and function. As with all forms of tooth wear, it is critical to consider the age of the individual and the expected rate of tooth wear. Generally, physiological cervical wear is a chronic and slow process. Tooth wear can be considered physiological in older individuals when the tooth in question is not at risk for fracture or pulp exposure and would be seen to last through the patient's lifetime without operative intervention. However, if the tooth wear is likely to compromise the long-term prognosis of the tooth, operative intervention may be required. Also in these circumstances, when abfraction lesions are painless and do not affect esthetics, there is normally no complaint from the patient. In such cases and in cases where the lesions do not cause severe clinical consequences and/or are shallow in depth $(<1 \mathrm{~mm})$, it is advisable to monitor the progression of these lesions at regular intervals without any treatment intervention. The assessment of lesion activity can be performed every 6 months to 12 months and during regular hygiene visits.

\section{Occlusal adjustment and occlusal splints}

As a result of the reported associations between occlusal stress and abfraction lesions, occlusal adjustment has been proposed as an alternative treatment to prevent the initiation and progression of these lesions and to minimize failure of cervical restorations. ${ }^{15,41}$ Occlusal adjustment may involve altering cuspal inclines, reducing heavy contacts, and removing premature contacts. However, the effectiveness of this type of intervention is not supported by evidence. $5,18,24$ In fact, inappropriate occlusal adjustments may increase the risk of certain conditions such as caries, occlusal tooth wear, and dentinal hypersensitivity. Devices claiming to assist the clinician in adjusting the occlusion and therefore managing abfraction should also be considered with caution. As previously suggested, if abfraction is suspected to be a dominant factor in the etiology of NCCLs, then any decision to carry out destructive, irreversible treatment, such as occlusal adjustment, should be considered very carefully. ${ }^{5}$ Occlusal splints to reduce the amount of nocturnal bruxism and nonaxial tooth forces have also been recommended to prevent the initiation and progression of abfraction lesions. ${ }^{32}$ While occlusal splints provide a conservative treatment option for managing suspected lesions, there is no evidence to support their use.

\section{Issue of hypersensitivity}

Dentinal hypersensitivity is characterized by short, sharp pain in response to a stimulus. Tooth sensitivity may be a temporary symptom associated with early stages of abfraction lesions. It is expected that the chronic nature of abfraction, which is accompanied by the natural process of dentinal remineralization, will slowly relieve tooth sensitivity. If sensitivity persists, the exposed dentin may require therapeutic treatment to relieve or eliminate the 
discomfort. ${ }^{42,43}$ There is a broad spectrum of noninvasive and relatively cost-effective treatment options that aim to partially or completely obstruct the open dentinal tubules, including in-office application of an adhesive layer, desensitizers, or fluoride varnish to the affected area and at-home use of high concentration fluoride and arginine products or desensitizing toothpastes containing potassium nitrate or even silver diamine fluoride. ${ }^{44} 46$ Different types of lasers have also been introduced as an alternative option for treating tooth sensitivity, but their clinical efficacy is unclear. ${ }^{47}$

Dentinal desensitizers, such as GLUMA (Heraeus Kulzer GmbH, Hanau, Germany), contain hydroxyethyl methacrylate that blocks the tubules and glutaraldehyde that causes the coagulation of plasma proteins of the dentinal fluid, thus resulting in a decrease of permeability. Dentin bonding agents and varnishes work as temporary sealants of the dentinal tubules. Yet, treating dentinal hypersensitivity remains a challenge for clinicians and patients. The placement of a restoration may only be required in extreme cases of hypersensitivity persistence after an unsuccessful response to these noninvasive options. Restorations should allow for the establishment of a physicomechanical barrier for dentinal protection against the causes of sensitivity or etiological risk factors leading to biocorrosion of the enamel-dentin substrates. Resin-based composites (RBCs) and resin-modified glass ionomer cement (RMGIC) restorations were reported to significantly reduce dentinal sensitivity initially but were also associated with increased sensitivity to air and cold, respectively, in $20 \%$ to $30 \%$ of restored NCCLs when evaluated at 6 months. ${ }^{48}$

\section{Restorative treatment}

The value of restorative dentistry to treat NCCLs remains a questionable issue in dentistry. ${ }^{39}$ It should be noted that failure of restorations placed to treat NCCLs is commonly observed, because the multifactorial etiology of these lesions may not be managed effectively. Figure 3 illustrates a clinical case of restorative treatment of NCCLs, in which the etiological factors were not addressed, leading to the continued progression of lesions and failure of restorations. Restorative challenges for these lesions are also attributed to difficulty with moisture control, in gaining access to subgingival margins, ${ }^{5,38}$ and in treating the sclerotic dentin, the most affected tissue due to these defects, with adhesive techniques. ${ }^{40}$ Occlusal loads, quality of dental substrates, ${ }^{15,49,50}$ and mechanical properties of restorative materials ${ }^{51}$ have been considered as important factors affecting the retention and clinical performance of NCCL restorations.
There are no generally accepted, specific guidelines in the literature stating when abfraction lesions should be restored. Nevertheless, there is no evidence that restorative treatment of NCCLs is effective in impeding further development of the lesions, and therefore, restorations cannot be used as a preventive measure to stop lesion progression. Here, we suggest that restorative treatment of abfraction lesions should be considered only when one or more of the following conditions are present: 1) active, cavitated carious lesions associated with abfraction lesions; caries risk assessment must be conducted to determine the most appropriate caries management plan to address patient risk factors and oral hygiene compliance, 2) cervical margins or all lesion margins are located subgingivally and preclude plaque control, hence increasing the risk for caries and periodontal disease, 3 ) extensive tooth structure loss, which compromises the integrity of the tooth, or the defect is in close proximity to the pulp, or the pulp has been exposed, 4) persistent dentinal hypersensitivity, in which noninvasive therapeutic options have failed, 5) prosthetic abutment, and 6) esthetic demands by patient request.

Prosthetic restorations may be necessary to restore abfraction lesions in teeth that are planned as an abutment for a removable partial denture. In these situations, the clinician has to account for the axial load distribution to avoid excessive occlusal stress on the cervical restoration. RBC restorations offer a favorable esthetic result, but the insertion and removal of the prosthesis, particularly the clasp, may accelerate the wear of the restoration.

Esthetics and appearances have made dental treatment more demanding. As professionals, dentists should not impose their esthetic concerns on the patient. Guidelines for the enhancement of esthetics may help the patient when selecting treatment options after they have recognized their goals. A smile analysis must be conducted in order to achieve the desirable results of cervical restorations. ${ }^{52}$ Perhaps a patient with a low smile line may not need any restorative treatment after all. It is also important to consider that cervical restorations may contribute to increased plaque accumulation potentially leading to the initiation and further development of caries and periodontal disease. Thus, one must conduct a risk-benefit analysis when considering restorative treatment of abfraction lesions. If there is a need for placement of restoration, NCCLs should be restored as minimally invasive as possible. Another important factor deserving attention while planning for the restoration of abfraction lesions is the restoration retention. It has been reported that many factors affect restoration retention, such as tooth location, patient's age, and occlusion. ${ }^{53}$ Authors have suggested that 
during the selection of restorative materials for cervical lesions, materials with a low modulus of elasticity, good adhesion to dentin, resistance to wear, and ability to endure acid dissolution should be considered. ${ }^{7,8,39,54}$ Of the available restorative techniques, adhesive systems, specifically RBCs, are the preferred choice of dentists to restore NCCLs, likely due to their esthetic and more conservative components. ${ }^{14,55}$ Although the use of GICs, RMGICs, and the lamination technique of GICRMGIC with RBC has been advocated for NCCL restorations, ${ }^{50,56}$ these materials are not frequently used. ${ }^{14}$ Only a few long-term clinical studies have evaluated the performance of the different restorative materials on cervical lesions. ${ }^{53,57-59}$ A systematic review evaluated the clinical effectiveness of contemporary adhesives for the restoration of NCCLs in terms of restoration retention as a function of time. ${ }^{55}$ Overall, glass ionomer and milder types of self-etch adhesive restorations revealed the best results in the context of clinical bonding effectiveness. ${ }^{55}$

\section{Root coverage surgical procedures}

Abfraction lesions may be associated with gingival recession, ie, the gingival margins of the affected teeth migrate apically, exposing root surfaces to the oral cavity. ${ }^{60}$ According to Miller's classification, ${ }^{61}$ there is no loss of interdental periodontal attachment and bone in classes I and II gingival recessions, and complete root coverage (up to the level of the cementoenamel junction [CEJ]) can be expected. In classes III and IV gingival recessions, mild/moderate and severe loss of interdental periodontal attachment are present, respectively, and root coverage is either partial or not possible. Other important factors such as tooth rotation, extrusion, and a clinically nonidentifiable CEJ may also impact the degree of root coverage. ${ }^{62}$ Specifically, the CEJ is an important anatomical structure to determine the degree of root coverage. ${ }^{61}$ Although several surgical procedures have been proposed for coverage of exposed root surface, ${ }^{63}$ it is important to consider that abfraction lesions are not limited to the root surfaces. In most cases of lesions associated with gingival recession, there is a loss of the hard tissues of the tooth crown causing the CEJ to disappear, and root coverage procedures are not effective at treating these crown defects. Consequently, a combined restorative-surgical approach may be indicated in these clinical situations. ${ }^{64}$

In the combined restorative-surgical approach, the restoration must be placed prior to the surgical procedure for better visibility of the operative field and for the finished restoration to provide a stable, hard, and convex substrate for the coronally advanced flap (CAF). ${ }^{63,64}$ To properly restore the dental tissues lost due to abfraction, the maximal level of root coverage needs to be predetermined. ${ }^{65}$ That is, the approximate future location of the gingival margin after the healing process must be determined prior to surgery in order to indicate the approximate apical level of restoration at the root surface. The restoration must recreate not only the contour of the tooth crown but also the contour of the lost CEJ at the root portion. ${ }^{66}$

Recent systematic reviews have pointed out that the combination of CAF with connective tissue graft (CTG) provides the best clinical outcomes for root coverage when appropriately performed. ${ }^{67,68}$ The need for CTG in association with CAF increases when root depressions that are mostly due to abrasion lesions are present and located apically to the restoration performed. In these cases, CTG prevents the collapse of the flap into the depressions, which could lead to undesirable outcomes of the root coverage procedure. ${ }^{69}$ Poor esthetic outcomes may also be related to the use of free gingival grafts, where the scar appearance and lighter pink color of the grafted area differ significantly from those of the adjacent gingival/mucosal tissue ${ }^{63}$ Free gingival grafts may be useful for augmenting the height of keratinized tissue in NCCL areas, but not for root coverage. ${ }^{63}$ In summary, the restorative-surgical approach may be recommended as a treatment option for abfraction lesions associated with deep root abrasions. The restoration must recreate the lost CEJ at the position of the maximal level of root coverage followed by the surgical procedure of combining CTG with $\mathrm{CAF}^{64,69}$

\section{Conclusion}

Abfractions lesions, as any other NCCLs, have a multifactorial etiology. A combination of different etiological factors will result in the initiation and further development of abfraction lesions that may differ in their clinical appearances. Identification and management of potential etiological factors are crucial for proper diagnosis and treatment planning. There is no conclusive evidence for reliable, predictable, and successful treatment regimens for abfraction lesions.

\section{Disclosure}

The authors report no conflicts of interest in this work.

\section{References}

1. Mjor IA. Pulp-dentin biology in restorative dentistry. Part 5: clinical management and tissue changes associated with wear and trauma. Quintessence Int. 2001;32(10):771-788.

2. Bartlett DW, Shah P. A critical review of non-carious cervical (wear) lesions and the role of abfraction, erosion, and abrasion. $J$ Dent Res. 2006;85(4):306-312.

3. Lee WC, Eakle WS. Possible role of tensile stress in the etiology of cervical erosive lesions of teeth. J Prosthet Dent. 1984;52(3):374-380. 
4. Grippo JO. Abfractions: a new classification of hard tissue lesions of teeth. J Esthet Dent. 1991;3(1):14-19.

5. Michael JA, Townsend GC, Greenwood LF, Kaidonis JA. Abfraction: separating fact from fiction. Aust Dent J. 2009;54(1):2-8.

6. Grippo JO, Simring M, Coleman TA. Abfraction, abrasion, biocorrosion, and the enigma of noncarious cervical lesions: a 20-year perspective. J Esthet Restor Dent. 2012;24(1):10-23.

7. Aw TC, Lepe X, Johnson GH, Mancl L. Characteristics of noncarious cervical lesions: a clinical investigation. J Am Dent Assoc. 2002;133(6):725-733.

8. Lee WC, Eakle WS. Stress-induced cervical lesions: review of advances in the past 10 years. J Prosthet Dent. 1996;75(5):487-494.

9. Levitch LC, Bader JD, Shugars DA, Heymann HO. Non-carious cervical lesions. J Dent. 1994;22(4):195-207.

10. Mayhew RB, Jessee SA, Martin RE. Association of occlusal, periodontal, and dietary factors with the presence of non-carious cervical dental lesions. Am J Dent. 1998;11(1):29-32.

11. LittleStar ML, Summitt JB. Non-carious cervical lesions: an evidenced-based approach to their diagnosis. Tex Dent J. 2003; 120(10):972-980.

12. Bader JD, Levitch LC, Shugars DA, Heymann HO, McClure F. How dentists classified and treated non-carious cervical lesions. J Am Dent Assoc. 1993;124(5):46-54.

13. Bader ID, Shugars DA. Variation in clinical decision making related to caries. In: Fejerskov O, Kidd E, editors. Dental Caries: The Disease and Its Clinical Management. 2nd ed. Copenhagen: Blackwell Munksgaard Ltd; 2008:555-574.

14. Nascimento MM, Gordan VV, Qvist V, et al; Dental Practice-Based Research Network Collaborative Group. Restoration of noncarious tooth defects by dentists in The Dental Practice-Based Research Network. J Am Dent Assoc. 2011;142(12):1368-1375.

15. Ichim IP, Schmidlin PR, Li Q, Kieser JA, Swain MV. Restoration of non-carious cervical lesions part II. Restorative material selection to minimise fracture. Dent Mater. 2007;23(12):1562-1569.

16. Lee HE, Lin CL, Wang $\mathrm{CH}$, Cheng $\mathrm{CH}$, Chang $\mathrm{CH}$. Stresses at the cervical lesion of maxillary premolar - a finite element investigation. J Dent. 2002;30(7-8):283-290.

17. Rees JS. The biomechanics of abfraction. Proc Inst Mech Eng $H$. 2006;220(1):69-80.

18. Silva AG, Martins CC, Zina LG, et al. The association between occlusal factors and noncarious cervical lesions: a systematic review. J Dent. 2013;41(1):9-16.

19. Lynch CD, O’Sullivan VR, Dockery P, McGillycuddy CT, Sloan AJ. Hunter-Schreger Band patterns in human tooth enamel. J Anat. 2010;217(2):106-115.

20. Rees JS, Hammadeh M, Jagger DC. Abfraction lesion formation in maxillary incisors, canines and premolars: a finite element study. Eur J Oral Sci. 2003;111(2):149-154.

21. Hammadeh M, Rees JS. The erosive susceptibility of cervical versus occlusal enamel. Eur J Prosthodont Restor Dent. 2001;9(1):13-17.

22. McCoy G. The etiology of gingival erosion. J Oral Implantol. 1982;10(3):361-362.

23. McCoy G. On the longevity of teeth. J Oral Implantol. 1983;11(2): 248-267.

24. Wood ID, Kassir AS, Brunton PA. Effect of lateral excursive movements on the progression of abfraction lesions. Oper Dent. 2009;34(3):273-279.

25. Pintado MR, Delong R, Ko CC, Sakaguchi RL, Douglas WH. Correlation of noncarious cervical lesion size and occlusal wear in a single adult over a 14-year time span. J Prosthet Dent. 2000;84(4): 436-443.

26. Estafan A, Furnari PC, Goldstein G, Hittelman EL. In vivo correlation of noncarious cervical lesions and occlusal wear. J Prosthet Dent. 2005;93(3):221-226.

27. Levrini L, Di Benedetto G, Raspanti M. Dental wear: a scanning electron microscope study. Biomed Res Int. 2014;2014:340425.
28. Wada I, Shimada Y, Ikeda M, et al. Clinical assessment of non carious cervical lesion using swept-source optical coherence tomography. J Biophotonics. 2015;8(10):846-854.

29. Sarode GS, Sarode SC. Abfraction: a review. J Oral Maxillofac Pathol. 2013;17(2):222-227.

30. Grippo JO, Simring M, Schreiner S. Attrition, abrasion, corrosion and abfraction revisited: a new perspective on tooth surface lesions. J Am Dent Assoc. 2004;135(8):1109-1118. [quiz 63-65].

31. Paryag A, Rafeek R. Dental erosion and medical conditions: an overview of aetiology, diagnosis and management. West Indian Med J. 2014;63(5):499-502.

32. Hur B, Kim HC, Park JK, Versluis A. Characteristics of non-carious cervical lesions - an ex vivo study using micro computed tomography. J Oral Rehabil. 2011;38(6):469-474.

33. Mjor IA, Sveen OB, Heyeraas KJ. Pulp-dentin biology in restorative dentistry. Part 1: normal structure and physiology. Quintessence Int. 2001;32(6):427-446.

34. Kaidonis JA, Richards LC, Townsend GC. Non-carious changes to tooth crowns. In: Mount GJ, Hume WR, editors. Preservation and Restoration of Tooth Structure. 2nd ed. Varsity Lakes, QLD: Varsity Lakes; 2005:47-60.

35. Bardsley PF. The evolution of tooth wear indices. Clin Oral Investig. 2008;12(suppl 1):S15-S19.

36. Smith BG, Knight JK. An index for measuring the wear of teeth. Br Dent J. 1984;156(12):435-438.

37. Loomba K, Bains R, Bains VK, Loomba A. Proposal for clinical classification of multifactorial noncarious cervical lesions. Gen Dent. 2014;62(3):39-44.

38. Brackett WW, Dib A, Brackett MG, Reyes AA, Estrada BE. Two-year clinical performance of Class $\mathrm{V}$ resin-modified glass-lonomer and resin composite restorations. Oper Dent. 2003;28(5):477-481.

39. Wood I, Jawad Z, Paisley C, Brunton P. Non-carious cervical tooth surface loss: a literature review. J Dent. 2008;36(10):759-766.

40. Duke ES, Lindemuth J. Polymeric adhesion to dentin: contrasting substrates. Am J Dent. 1990;3(6):264-270.

41. Piotrowski BT, Gillette WB, Hancock EB. Examining the prevalence and characteristics of abfractionlike cervical lesions in a population of U.S. veterans. J Am Dent Assoc. 2001;132(12):1694-1701. [quiz 726-727].

42. Jena A, Shashirekha G. Comparison of efficacy of three different desensitizing agents for in-office relief of dentin hypersensitivity: a 4 weeks clinical study. J Conserv Dent. 2015;18(5):389-393.

43. Baysan A, Lynch E. Treatment of cervical sensitivity with a root sealant. Am J Dent. 2003;16(2):135-138.

44. Sharif MO, Iram S, Brunton PA. Effectiveness of arginine-containing toothpastes in treating dentine hypersensitivity: a systematic review. J Dent. 2013;41(6):483-492.

45. Beddis H, Soneji P, Welford S, Ashley M. Making sense of sensitivity. Dent Update. 2013;40(5):403-404.

46. Petersson LG. The role of fluoride in the preventive management of dentin hypersensitivity and root caries. Clin Oral Investig. 2013; 17(suppl 1):S63-S71.

47. Sgolastra F, Petrucci A, Severino M, Gatto R, Monaco A. Lasers for the treatment of dentin hypersensitivity: a meta-analysis. J Dent Res. 2013;92(6):492-499.

48. Powell LV, Gordon GE, Johnson GH. Sensitivity restored of Class V abrasion/erosion lesions. J Am Dent Assoc. 1990;121(6):694-696.

49. Lambrechts P, Van Meerbeek B, Perdigao J, Gladys S, Braem M, Vanherle G. Restorative therapy for erosive lesions. Eur J Oral Sci. 1996;1042(pt 2):229-240.

50. Francisconi LF, Graeff MS, Martins Lde M, et al. The effects of occlusal loading on the margins of cervical restorations. J Am Dent Assoc. 2009;140(10):1275-1282.

51. Brackett WW, Robinson PB. Composite resin and glass-ionomer cement: current status for use in cervical restorations. Quintessence Int. 1990;21(6):445-447. 
52. Tjan AH, Miller GD, The JG. Some esthetic factors in a smile. J Prosthet Dent. 1984;51(1):24-28.

53. Heymann HO, Sturdevant JR, Bayne S, Wilder AD, Sluder TB, Brunson WD. Examining tooth flexure effects on cervical restorations: a two-year clinical study. J Am Dent Assoc. 1991;122(5):41-47.

54. Osborne-Smith KL, Burke FJ, Wilson NH. The aetiology of the noncarious cervical lesion. Int Dent J. 1999;49(3):139-143.

55. Peumans M, De Munck J, Mine A, Van Meerbeek B. Clinical effectiveness of contemporary adhesives for the restoration of non-carious cervical lesions. A systematic review. Dent Mater. 2014;30(10): 1089-1103.

56. Tyas MJ. The Class V lesion - aetiology and restoration. Aust Dent J. 1995;40(3):167-170.

57. Smales RJ, Ng KK. Longevity of a resin-modified glass ionomer cement and a polyacid-modified resin composite restoring noncarious cervical lesions in a general dental practice. Aust Dent $J$. 2004;49(4):196-200.

58. Heintze SD, Roulet JF. Glass ionomer derivates have better retention rates in cervical restorations compared to self-etching adhesive systems. J Evid Based Dent Pract. 2010;10(1):18-20.

59. Franco EB, Benetti AR, Ishikiriama SK, et al. 5-year clinical performance of resin composite versus resin modified glass ionomer restorative system in non-carious cervical lesions. Oper Dent 2006;31(4):403-408.

60. Wennstrom JL. Mucogingival surgery. In: Lang NP, Karring T, editors Proceedings of the 1st European Workshop on Periodontology. London: Quintessence; 1994:193-209.
61. Miller PD Jr. A classification of marginal tissue recession. Int $J$ Periodontics Restorative Dent. 1985;5:8-13.

62. Zucchelli G, Testori T, De Sanctis M. Clinical and anatomical factors limiting treatment outcomes of gingival recession: a new method to predetermine the line of root coverage. J Periodontol. 2006;77(4):714-721.

63. Zucchelli G, Mounssif I. Periodontal plastic surgery. Periodontol 2000. 2015;68(1):333-368.

64. Zucchelli G, Gori G, Mele M, et al. Non-carious cervical lesions associated with gingival recessions: a decision-making process. J Periodontol. 2011;82(12):1713-1724.

65. Zucchelli G, Mele M, Stefanini M, et al. Predetermination of root coverage. J Periodontol. 2010;81(7):1019-1026.

66. Cairo F, Nieri M, Cattabriga M, et al. Root coverage esthetic score after treatment of gingival recession: an interrater agreement multicenter study. J Periodontol. 2010;81(12):1752-1758.

67. Cairo F, Nieri M, Pagliaro U. Efficacy of periodontal plastic surgery procedures in the treatment of localized facial gingival recessions. A systematic review. J Clin Periodontol. 2014;41(suppl 15):S44-S62.

68. Graziani F, Gennai S, Roldan S, et al. Efficacy of periodontal plastic procedures in the treatment of multiple gingival recessions. $J$ Clin Periodontol. 2014;41(suppl 15):S63-S76.

69. Cortellini P, Pini Prato G. Coronally advanced flap and combination therapy for root coverage. Clinical strategies based on scientific evidence and clinical experience. Periodontol 2000. 2012;59(1):158-184.

70. Marus R. Esthetic and predictable treatment of abfraction lesions. Inside Dentistry. 2011;7(6).
Clinical, Cosmetic and Investigational Dentistry

\section{Publish your work in this journal}

Clinical, Cosmetic and Investigational Dentistry is an international, peer-reviewed, open access, online journal focusing on the latest clinical and experimental research in dentistry with specific emphasis on cosmetic interventions. Innovative developments in dental materials, techniques and devices that improve outcomes and patient satisfac-

\section{Dovepress}

tion and preference will be highlighted. The manuscript management system is completely online and includes a very quick and fair peerreview system, which is all easy to use. Visit http://www.dovepress. com/testimonials.php to read real quotes from published authors. 